Hagh-Shenas, H., Goodarzi, M. A., Dehbozorgi, G., et al (2005) Psychological consequences of the Bam earthquake on professional and nonprofessional helpers. Journal of Traumatic Stress, 18, 477-483

Janoff-Bulman, R. (1992) Shattered Assumptions - Towards a New Psychology of Trauma. Free Press.

Makdum, M. \& Javed, A. (2006) Earthquake in Pakistan and Kashmir: suggested plan for psychological trauma relief work. International Psychiatry, 3(1), 16-18

Niaz, U., Hassan, S., Hassan, M., et al (2006) Prevalence of posttraumatic stress disorder and co-morbid depression in earthquake survivors in NWFP, Pakistan: a preliminary study. Journal of Pakistan Psychiatric Society, 3, 98-101.
Norris, F., Stevens, S., Pfefferbaum, B., et al (2008) Community resilience as a metaphor, theory, set of capacities, and strategy for disaster readiness. American Journal of Community Psychology, 41, 127-150.

Simonsen, L. F. \& Reyes, G. (2003) Community-Based Psychological Support - A Training Manual (1st edition). International Federation of Red Cross and Red Crescent Societies.

Taylor, A. J. (2001) Spirituality and personal values: neglected components of trauma treatment. Traumatology, 7, 125-135.

Van Griensven, F., Chakkraband, M., Theinkura, W., et al (2006) Mental health problems among adults in tsunami-affected areas in southern Thailand. JAMA, 296, 537-548.

\title{
Introducing competency-based training in Europe: an Anglo-Dutch perspective
}

\section{Clare Oakley, ${ }^{1}$ Amit Malik ${ }^{2}$ and Femke Kamphuis ${ }^{3}$}

'Specialty Registrar, Queen Elizabeth Psychiatric Hospital, Birmingham B15 2QZ, UK, email clareoakley@doctors.org.uk 2President, European Federation for all Psychiatric Trainees (EFPT), Gosport War Memorial Hospital, Gosport, Hampshire PO12 3PW, UK ${ }^{3}$ Psychiatric trainee, Symfora Groep location Zon en Schild, Utrechtseweg 266, Amersfoort, The Netherlands

$T^{T}$ here are striking and significant differences in psychiatric training across Europe and procedures for the assessment of trainees vary widely (Strachan, 2007). The introduction of competency-based training represents a major shift in medical education and a challenge to harmonising psychiatric training in Europe. This paper discusses the development and implementation of competency-based training in the Netherlands and the UK and focuses on its effects on trainees.

\section{Structure of training}

The structure of medical training and postgraduate training in psychiatry in the UK and the Netherlands is largely similar. However, the minimum duration of postgraduate training is 1.5 years shorter in the Netherlands and there are fewer subspecialties that Dutch trainees can qualify in.

\section{Drivers for change}

In 2004, the Dutch health minister adopted recommendations made by a committee investigating the reorganisation of healthcare. It was recommended that the training of health professionals be more focused on everyday practice and that professionals with a high degree of skill and experience be used to perform only certain tasks, those that could not be done by other, less well-trained, and thus less expensive, professionals. These recommendations were also related to a Dutch report on the division of tasks among mental health professionals (Vleugel et al, 2008). Conceptually, this is similar to 'New Ways of Working' in the UK, which aims to use the skills, knowledge and experience of consultant psychiatrists to best effect by concentrating on those patients with the most complex needs and encouraging other team members to take on increased responsibility (Department of Health, 2005).
In the Netherlands, it has been felt for some time that trainees should not be judged only on their knowledge and practical skills, but also systematically assessed on broader competencies, such as team-working skills, communication skills and professionalism. Additionally, more emphasis on the transparency of healthcare organisations, not only regarding financial aspects, but also regarding training and treatment strategies, has led to greater use of care pathways (diagnosis and treatment combinations) and records of activities performed by health professionals. Organisations receive their funding according to predefined tariffs that are based on diagnosis-treatment combinations, and this puts more pressure on professionals to perform certain tasks in a limited amount of time. Training is not part of these provisions and so in 2008 the funding of training will be changed. In the UK, financial arrangements for healthcare funding are also changing along Dutch lines, with the introduction of payment-by-results, which essentially bases funding on predefined tariffs for care pathways. Once again, there are no set tariffs for training and the manner in which training is funded centrally may change.

In 2005, the Postgraduate Medical Education and Training Board (PMETB) became the UK's statutory body for quality and standards in postgraduate medical education. The new competency-based curriculum approved by the PMETB (Royal College of Psychiatrists, 2006) focuses achievement in medical training on the attainment of specific competencies related not only to clinical care but also to broader skills, as mentioned above. Consequently, the performance of the doctor in the workplace will provide a more robust measure of overall competence. The PMETB is required to approve all aspects of the curriculum and assessment programme, and has recommended an overarching assessment strategy consisting of workplace-based assessments and examinations of knowledge and clinical skills (Bhugra, 2006). A variety of workplace-based assessments (WPBAs) have been developed to allow trainees to demonstrate the required competencies. 


\section{Recommendations}

In the Netherlands and the UK, similar recommendations were drawn up for competency-based training.

o Competencies that psychiatrists have to acquire and demonstrate in their everyday practice should be defined.

O These competencies must be assessed in the workplace.

O Trainees must keep a portfolio.

O A trainee's progress must be assessed regularly by the trainee and trainer.

o There must be a combination of formative and summative assessments.

In the Netherlands the competencies were developed following the domains of the CanMEDS model: medical expert, communicator, collaborator, manager, health advocate, scholar and professional (Frank, 2005). In the UK the competencies were developed following the domains of Good Medical Practice: good clinical care, working with colleagues, probity and health (General Medical Council, 2001).

\section{Trainee involvement}

The Dutch Psychiatric Foundation charged a committee of trainers and trainees with the task of changing the curriculum and assessments. The leadership of both the Dutch and the British psychiatric trainees' associations were very involved in the development of the competency-based training model. In August 2006, 15 pilot sites across the UK began using at least one of the WPBA tools. This allowed trainees around the country the opportunity to give feedback on the feasibility of using the new tools and aid their further development.

\section{Assessments}

In the Netherlands, regular tests of theoretical knowledge will be combined with WPBA. Training has been divided into themes according to work settings and during each placement a trainee will have different competencies assessed. The most important means of testing is with 'brief clinical encounters', where the trainee and supervisor will agree upon a specific competency to be tested, see a patient together and afterwards fill in an assessment form. Brief clinical encounters should be completed eight times a year, as this is the minimum number required to guarantee validity. The brief clinical encounter is equivalent to the mini-assessed clinical encounter in the UK, where a 15-minute aspect of a doctorpatient interaction is considered. In the UK, the WPBA tools will be used in conjunction with the Membership examination, the structure of which has been modified for 2008. There are detailed mandatory requirements regarding WPBAs for each year of postgraduate psychiatric training in the UK. The other WPBA tools being used are listed in Table 1.

\section{Trainee concerns}

On the whole, Dutch psychiatric trainees are not very aware of the upcoming changes, which are being implemented this year. The Dutch Psychiatric Trainees' Association is trying to address this issue and inform trainees. Although the Association is enthusiastic about the implementation of competency-based training, it is concerned that not specifying
Table 1 Comparison of workplace-based assessment tools used in the Netherlands and the UK

\begin{tabular}{|c|c|}
\hline $\begin{array}{l}\text { Assessment tools in } \\
\text { the Netherlands }\end{array}$ & $\begin{array}{l}\text { Assessment tools in } \\
\text { the UK }\end{array}$ \\
\hline Brief clinical encounter & Mini-assessed clinical encounter \\
\hline 360-degree appraisal & Mini-peer assessment tool \\
\hline Evaluation of a medical file & Case-based discussion \\
\hline Case presentation & Case presentation \\
\hline Critical appraisal presentation & Journal club \\
\hline Writing a legal report & - \\
\hline $\begin{array}{l}\text { Presenting patient problems } \\
\text { to colleagues after having } \\
\text { been on call }\end{array}$ & - \\
\hline $\begin{array}{l}\text { Evaluation of a discharge } \\
\text { summary }\end{array}$ & - \\
\hline- & Assessment of clinical expertise \\
\hline- & Assessment of teaching \\
\hline- & Directly observed procedural skills \\
\hline
\end{tabular}

the minimum number of hours of training will lead to a reduction in quality of training in the future. The specification of hours has served as an important tool for trainers in negotiating adequate educational staff numbers with their employing organisations. The Association will therefore strive to make some concrete requirements that organisations have to comply with in order to obtain the right to teach trainees.

Similarly, in the UK trainees are not very knowledgeable about the new requirements for WPBA, as it has been overshadowed by the introduction of 'Modernising Medical Careers' (MMC) and the difficulties of the Medical Training Application System (MTAS). The failures of MTAS for specialty selection caused a great deal of anguish for trainees and resulted in low morale. Unfortunately, the unpopularity of MMC and MTAS mean that the introduction of WPBA is viewed by some as another unwanted, centralised imposition.

There are common concerns among psychiatric trainees in the UK and the Netherlands about the implementation of WPBAs. Both trainees and trainers need to be better informed about the implementation of competency-based training, its assessments and the potential benefits. There needs to be sufficient training for all professionals who will be used to assess trainees in the workplace, to ensure that the assessments are correctly undertaken and meaningful. It is felt that the time spent completing assessments may be in conflict with the amount of time spent treating patients, and it may be difficult to balance the time required for assessment with that for service delivery. If WPBAs are going to be used as summative assessments and thus decide trainees' progress through training, it is imperative that they are reliable and valid. Clearly, this will need to be monitored as the tools are implemented.

\section{The future}

The trainees' associations are trying to ensure that trainees have greater access to information about competency-based training and are aware of the changes. They will both have an important role in monitoring the implementation of competency-based training and how it affects trainees and their training. It is crucial that feedback from trainees and trainers is used to develop and improve the existing assessment tools. It is likely to be several years before the assessment tools are sufficiently reliable and valid. 


\section{Competency-based training elsewhere in Europe}

The overall emphasis in postgraduate psychiatric training in Western Europe is shifting towards a competency-based model. Other countries, including Sweden and Denmark, are also developing their systems of training and assessment. Close collaboration between the various national systems will enhance the quality and validity of all the new competencybased models. This should be promoted not only bilaterally but also multilaterally, through international organisations such as Union Européenne des Médecins Spécialistes (UEMS) and the European Federation for all Psychiatric Trainees (EFPT). Both these organisations are already actively discussing competency-based training.

\section{Conclusion}

Competency-based training, once properly implemented, will allow a doctor's performance in the workplace to be reliably assessed. As this new model of training is implemented, the assessment tools need to be carefully evaluated and improved. It is hoped that competency-based training will lead to enhanced standards in postgraduate medical education, resulting in better training for trainees and better care for patients. The experiences of trainees in the Netherlands and the UK will be useful for trainees in other parts of Europe as competency-based training is implemented there.

\section{References}

Bhugra, D. (2006) The new curriculum for psychiatric training. Advances in Psychiatric Treatment, 12, 393-396.

Department of Health (2005) New Ways of Working for Psychiatrists: Enhancing Effective, Person-Centred Services Through New Ways of Working in Multi-Agency Contexts. Department of Health.

Frank, J. R. (2005) The CanMEDS 2005 Physician Competency Framework. Better Standards. Better Physicians. Better Care. Royal College of Physicians and Surgeons of Canada.

General Medical Council (2001) Good Medical Practice (3rd edition). GMC. Royal College of Psychiatrists (2006) A Competency Based Curriculum for Specialist Training in Psychiatry. RCPsych. See http://www.rcpsych. ac.uk/training/curriculum.aspx (accessed August 2008).

Strachan, J. G. (2007) Training in Europe in perspective. International Psychiatry, 4, 33-34.

Vleugel, E. E., Glas, G. \& Hengeveld, M. W. (2008) Herziening Opleiding en Onderwijs Psychiatrie (HOOP) (in press).

\section{Reduced membership rates}

The Royal College of Psychiatrists has reduced its annual subscription rates to $£ 30$ for members working in countries classed as B and C or D according to the World Bank criteria if their monthly income in 2008 is below $f 1000$. Further details are available from the College Membership Office.

\section{Bursary for psychiatrists from low-income countries}

The College's Faculty of the Psychiatry of Old Age has a bursary for psychiatrists practising in low-income countries in the field of mental health in older people, to attend the annual residential meeting in Barcelona on 5-6 March 2009. Further information is available from kkottasz@rcpsych.ac.uk.

\section{Specialist Associateship}

In July 2008 the College launched a new grade of membership, Specialist Associateship, open to registered specialists who qualified abroad but who currently work in the UK. Further information is available from latkinson@rcpsych. ac.uk.

\section{The launch of BACAMH}

The Bangladesh Association for Child and Adolescent Mental Health (BACAMH) was launched in May 2008. Its mission is to promote the mental health of children, adolescents and their families through training, research, prevention and collaboration. See the Association's website, http://www. bacamh.99homepages.com.

\section{A visit to Iraqi Kurdistan}

ir: The Iraq Subcommittee (ISC) of the Board of International Affairs organised a visit to Iraqi Kurdistan to help support mental health services within the province. Four members of the Subcommittee took part in the visit, on 8-15 June 2007. Our official meetings started on the day of our arrival. We met with the dean of Hawler Medical
School, the president of Hawler Medical University and the dean of Hawler Nursing School, as well as the Minister of Health and the Minister of Higher Education (Hawler is the Kurdish name for Erbil, capital of the province). We also visited the mental health unit in Hawler Hospital and met with the consultants, psychiatric trainees and other staff. We also visited a newly commissioned long-stay psychiatric facility. 